\title{
Cause and predictors of neonatal mortality among neonates admitted to neonatal intensive care units of public hospitals in eastern Ethiopia: a facility-based prospective follow-up study
}

Assefa Desalew ${ }^{1 *}$, Yitagesu Sintayehu' ${ }^{1}$ Nardos Teferi ${ }^{2}$, Firehiwot Amare ${ }^{3}$, Bifitu Geda ${ }^{1}$, Teshager Worku', Kebebush Abera ${ }^{1}$ and Abiyot Asefaw ${ }^{1}$

\begin{abstract}
Background: The first month is the most crucial period for child survival. Neonatal mortality continues to remain high with little improvement over the years in Sub-Saharan Africa, including Ethiopia. This region shows the least progress in reducing neonatal mortality and continues to be a significant public health issue. In this study setting, the causes and predictors of neonatal death in the neonatal intensive care units are not well documented. Hence, this study aimed to determine the causes and predictors of neonatal mortality among infants admitted to neonatal intensive care units in eastern Ethiopia.

Methods: A facility-based in prospective follow-up study was conducted among neonates admitted to neonatal intensive care units of public hospitals of eastern Ethiopia from November 1 to December 30, 2018. Data were collected using a pretested structured questionnaire and a follow-up checklist. The main outcomes and causes of death were set by pediatricians and medical residents. EpiData 3.1 and Statistical Package for Social Sciences Version 25 software were used for data entry and analysis, respectively. Multivariable logistic regression was used to identify the predictors of facility-based neonatal mortality.

Results: The proportion of facility-based neonatal mortality was 20\% (95\% Cl:16.7-23.8\%). The causes of death were complications of preterm birth (28.58\%), birth asphyxia (22.45\%), neonatal infection (18.36\%), meconium aspiration syndrome (9.18\%), respiratory distress syndrome (7.14\%), and congenital malformation (4.08\%). Low birth weight, preterm births, length of stay of the neonatal intensive care unit, low 5 min APGAR score, hyperthermia, and initiation of feeding were predictors of neonatal death among infants admitted to the neonatal intensive care units of public hospitals in eastern Ethiopia.

Conclusions: The proportion of facility-based neonatal deaths was unacceptably high. The main causes of death were preventable and treatable. Hence, improving the timing and quality of antenatal care is essential for early detection, anticipating high-risk newborns, and timely interventions. Furthermore, early initiation of feeding and better referral linkage to tertiary health facilities could lead to a reduction in neonatal death in this setting.
\end{abstract}

Keywords: Facility-based study, Neonatal mortality, Predictors, NICU, Ethiopia

\footnotetext{
* Correspondence: assefad100@gmail.com

'School of Nursing and Midwifery, College of Health and Medical Sciences, Haramaya University, Po. Box 235, Harar, Ethiopia

Full list of author information is available at the end of the article
}

(c) The Author(s). 2020 Open Access This article is licensed under a Creative Commons Attribution 4.0 International License, which permits use, sharing, adaptation, distribution and reproduction in any medium or format, as long as you give appropriate credit to the original author(s) and the source, provide a link to the Creative Commons licence, and indicate if changes were made. The images or other third party material in this article are included in the article's Creative Commons licence, unless indicated otherwise in a credit line to the material. If material is not included in the article's Creative Commons licence and your intended use is not permitted by statutory regulation or exceeds the permitted use, you will need to obtain permission directly from the copyright holder. To view a copy of this licence, visit http://creativecommons.org/licenses/by/4.0/ The Creative Commons Public Domain Dedication waiver (http://creativecommons.org/publicdomain/zero/1.0/) applies to the data made available in this article, unless otherwise stated in a credit line to the data. 


\section{Background}

The first month is the most crucial period for child survival. Globally, an estimated 2.5 million newborns die in the first month of life, approximately 7000 every day in 2017. Currently, an estimated 18 neonatal deaths per 1000 live births occur during the neonatal period $[1,2]$, accounting for $46 \%$ of under-five deaths [2, 3]. More than $70 \%$ of these early neonatal deaths were due to conditions that could be prevented or treated with access to simple and affordable interventions [1, 2, 4-8].

Moreover, $98 \%$ of neonatal deaths occur in developing countries with a greater burden occurring in Sub-Saharan Africa (SSA). In this region, approximately one million infant deaths occur in the first month of life, which represents the highest neonatal mortality rate (NMR) among those countries participating in the Sustainable Development Goals (SDGs) and shows the least progress in reducing the NMR $[1,3,6,9,10]$. The majority of these deaths are caused by infectious diseases, intrapartum asphyxia, pregnancyrelated complications, and premature births [11].

Neonatal death continues to remain a significant public health issue in Ethiopia, with only a slight reduction from 39 per 1000 live births in 2008 to 29 per 1000 live births in 2017 [12, 13]. Facility-based studies in Ethiopia indicated that the proportion of neonatal deaths was 14.3\% in Gondar and 23.3\% in Addis Ababa [13, 14]. Despite multiple efforts by both the government and other stakeholders, neonatal death remains higher in Ethiopia than in many developing countries [10]. Although the country is committed to achieving SDGs related to both maternal and child health, which was reflected in the Health sector development program IV and the Health sector transformation program, the benefit has not been achieved to date through a reduction in neonatal deaths. The Minister of Health is working collaboratively with the World Health Organization (WHO) to improve the quality of Neonatal Intensive Care Units (NICU) in health facilities; however, more is needed $[14,15]$.

The continued reduction in neonatal deaths is critical to progress towards achieving SDGs. Therefore, determining facilities-based causes and predictors of neonatal death in the Eastern Ethiopian context is crucial and essential. Due to the recent establishment of the NICU in this setting, data are limited in both the country and study setting. Hence, this study aimed to fill in these gaps and used them as inputs for policymakers and program implementers to design appropriate interventions that could contribute to the reduction of neonatal morbidity and mortality in Ethiopia.

\section{Methods}

\section{Study area, design, and population}

This facility-based prospective follow-up study was conducted among all neonates admitted to the NICU in eastern Ethiopia from November 1 to December 30, 2018. All public health institutions with the NICU facilities in the Harari regional state, Dire Dawa administration and eastern and western Hararghe Zone from the Oromia regional state were included. These facilities have been providing health services for an estimated 6, 565,406 populations in the catchment area. A total of 10 public hospitals in this study area provide NICU services. All neonates admitted to the NICU during the study period were included from six randomly selected public hospitals. However, neonates who were admitted for observation and without mothers or guardians during the study period were excluded.

\section{Sample size and sampling technique}

Even though we included all neonates consecutively admitted to the NICU, we checked the adequacy of the sample size using the formula for a double population proportion to determine the sample size using stat calc of Epi Info statistical software Version 7. A 95\% confidence level, power of $80 \%$, and an assumption of the ratio of unexposed to exposed equivalent to 1 was assumed for the calculation. Based on this, the sample size was calculated to be 468 . An addition of $5 \%$ was made for the nonresponse rate, and then the final sample size was 491 .

Ten public hospitals in eastern Ethiopia provide NICU services. Among these, six were selected using a simple random sampling technique: Garamuleta, Deder, Chiro, and Sabin Hospital, Dilchora Referral Hospital, and Hiwot Fana Specialized University Hospital were included in the study. Proportional allocation to size was used to distribute the calculated sample size based on the estimated case flow per month in each selected public hospital.

\section{Data collection methods}

A structured questionnaire and checklist adapted from a review of similar literature $[4,6,16]$ were used for data collection. The tool contained information related to obstetric and antenatal care (ANC) visits, age at admission, sex, gestational age at birth, APGAR score, admission diagnosis, birth weight, duration of hospital stay, need for ventilator support, neonatal outcomes, and causes of death. It was prepared in English and translated into local languages and then re-translated back into English to ensure consistency and understandability.

Maternal and demographic data were obtained by interviewing the mothers or reviewing the referral records by neonatal nurses, and each neonate was monitored daily until discharged or died. A final assessment of the cause of death was determined by a pediatrician or pediatric resident after conducting the necessary laboratory investigation and a thorough review of medical records. 
Prematurity was defined as a live-birth newborn delivered before 37 completed weeks. For participants with an unknown last normal menstrual period, residents used ultrasound and the new Ballard score to estimate the gestational age. Birth weight was classified using WHO weight classification and was measured upon admission using the digital infant weight scale (Seca) [17]. Birth asphyxia was diagnosed when the newborn had at least one of the following signs: not breathing or gasping, < 30 breaths per minute, or $<7$ APGAR score, had neonatal neurologic sequelae (seizures, coma, and hypotonia), or multiple organ involvement (kidney, lungs, liver, heart, and intestines) [16, 18].

\section{Data quality management}

A two-day intensive training was given to 12 neonatal nurses, pediatric residents, and pediatricians before data collection. The training consisted of the purpose of the study, enumeration procedures, and how to interview and follow-up the neonates. The tool was pre-tested, and necessary modifications were made for the local context before data collection. After data collection, all completed questionnaires were checked for completeness and cleaned manually. Double data entry was performed to check clarity.

\section{Statistical analysis}

The data were coded and entered into EpiData Version 3.1 and exported to the Statistical Package for Social Sciences (SPSS) Version 25 statistical software for analysis. Univariate analysis was used to describe the frequency distribution of each variable. The outcome variables were coded as " 1 " for died whereas "0" for improved. The association between the outcome variables (i.e., neonatal death) and independent variables was analyzed using a logistic regression model. Covariates with a $P$-value $<0.2$ were retained and entered into the multivariable logistic regression analysis using a forward stepwise approach.

Table 1 Characteristics of mothers whose neonates were admitted to the NICU of public hospitals in eastern Ethiopia, 2018 [ $n=489$ ]

\begin{tabular}{|c|c|c|c|}
\hline Characteristics & Category & Frequency & Percent \\
\hline \multirow[t]{4}{*}{ Age } & less than 20 years & 109 & 22.3 \\
\hline & $21-30$ years & 279 & 57.1 \\
\hline & $31-40$ years & 95 & 19.4 \\
\hline & $\geq 41$ years & 6 & 1.2 \\
\hline \multirow[t]{5}{*}{ Education level } & Unable to read and write & 198 & 40.5 \\
\hline & Able to read and write & 59 & 12.1 \\
\hline & Primary Education & 111 & 22.7 \\
\hline & Secondary Education & 80 & 16.4 \\
\hline & College and above & 41 & 8.4 \\
\hline \multirow[t]{4}{*}{ Marital status } & Single & 28 & 5.7 \\
\hline & Married & 452 & 92.4 \\
\hline & Divorced & 7 & 1.4 \\
\hline & Widowed & 2 & 0.4 \\
\hline \multirow[t]{2}{*}{ Residence } & Urban & 255 & 52.1 \\
\hline & Rural & 234 & 47.9 \\
\hline \multirow[t]{2}{*}{ ANC follow-up } & Yes & 378 & 77.3 \\
\hline & No & 111 & 22.7 \\
\hline \multirow[t]{2}{*}{ Place of ANC follow up } & Public & 320 & 65.4 \\
\hline & Private & 58 & 11.9 \\
\hline \multirow[t]{4}{*}{ Gestational age at the start of ANC follow up } & $<24$ weeks & 180 & 36.8 \\
\hline & 24-29 weeks & 149 & 30.5 \\
\hline & 30-35 weeks & 37 & 7.6 \\
\hline & greater than 35 weeks & 12 & 2.5 \\
\hline \multirow[t]{4}{*}{ Number of ANC follow up attended } & One & 37 & 7.6 \\
\hline & Two & 80 & 16.4 \\
\hline & Three & 145 & 29.7 \\
\hline & four and above & 116 & 23.7 \\
\hline
\end{tabular}


Hosmer and Lemeshow's goodness-of-fit test was used to assess whether the necessary assumptions were fulfilled. Adjusted odds ratio (AOR) with 95\% confidence intervals (CI) using a P-value $<0.05$ was considered as statistically significant association with the outcome variable.

\section{Results}

\section{Maternal socio-demographic and ANC characteristics}

A total of 489 neonates were admitted during the study period. Two hundred seventy-nine (57.1\%) mothers of the neonates were aged $21-30$ years with a mean age $( \pm$ $\mathrm{SD})$ of $26.44 \pm 6.04$ years. One hundred ninety-eight (40.5\%) and 452 (92.4\%) mothers were unable to read or write and married. Two hundred and fifty-five (52.1\%) participants were from urban residents. Regarding ANC follow-up, two-thirds of mothers 378 (77.33\%) had attended at least one prenatal visit; however, only 116 (23.7\%) had received the recommended ANC follow-up for their current pregnancy (which was 4 or more ANC visits). One hundred eighty (36.8\%) mothers started ANC follow-up before 24 weeks of gestation and 149 (30.5\%) started after 24-30 weeks of gestation (Table 1).

\section{Obstetric characteristics}

Two hundred eighty-three (57.9\%) neonates were delivered from multiparous mothers. Four hundred forty

Table 2 Obstetric characteristics of mothers whose neonates were admitted to the NICU of public hospitals in eastern Ethiopia, $2018[n=489]$

\begin{tabular}{|c|c|c|c|}
\hline Characteristics & Category & Frequency & Percent \\
\hline \multirow[t]{2}{*}{ Parity } & Primipara & 206 & 42.1 \\
\hline & Multipara & 283 & 57.9 \\
\hline \multirow[t]{2}{*}{ Type of pregnancy } & Single & 440 & 90.0 \\
\hline & Twins & 49 & 10.0 \\
\hline \multirow[t]{5}{*}{ Place of delivery } & At the index Hospital & 380 & 77.7 \\
\hline & Another hospital & 30 & 6.1 \\
\hline & Health center & 53 & 10.8 \\
\hline & Private facilities & 4 & 0.8 \\
\hline & Home & 22 & 4.5 \\
\hline \multirow[t]{6}{*}{ Birth attendant } & Midwife & 299 & 61.1 \\
\hline & Physician & 151 & 30.9 \\
\hline & Nurse & 11 & 2.2 \\
\hline & Health extension workers & 2 & 0.4 \\
\hline & Traditional birth attendants & 23 & 4.7 \\
\hline & Others & 3 & 0.6 \\
\hline \multirow[t]{3}{*}{ Duration of labor } & $<4$ hrs. & 43 & 8.8 \\
\hline & 4-12 hrs. & 288 & 58.9 \\
\hline & Greater than 12 hrs. & 158 & 32.3 \\
\hline \multirow[t]{3}{*}{ Amniotic fluid status during labor } & Clear & 360 & 73.6 \\
\hline & Meconium stained & 107 & 21.9 \\
\hline & Bloodstained & 22 & 4.5 \\
\hline \multirow[t]{3}{*}{ Mode of delivery } & Spontaneous Vaginal & 338 & 69.1 \\
\hline & Cesarean section & 122 & 24.9 \\
\hline & Instrumental Delivery & 29 & 5.9 \\
\hline \multirow[t]{4}{*}{ Gestational age at birth } & Very preterm(< 34 weeks) & 63 & 12.9 \\
\hline & Late preterm(34-36 weeks) & 97 & 19.8 \\
\hline & Term(37-42 weeks) & 319 & 65.2 \\
\hline & post-term(> 42 weeks) & 10 & 2.0 \\
\hline \multirow[t]{3}{*}{ Length of hospital stay } & $<3$ days & 160 & 32.7 \\
\hline & 4-7 days & 229 & 46.8 \\
\hline & $>7$ days & 100 & 20.4 \\
\hline
\end{tabular}


(90\%) were singleton and $380(77.7 \%)$ were delivered at the index hospital. Two hundred ninety-nine (61.1\%) mothers were delivered by midwives, and 288 (58.9\%) mothers had a labor duration ranging from 4 to $12 \mathrm{hrs}$. More than two-thirds 338 (69.1\%) of mothers were delivered through spontaneous vaginal delivery and 319 (65\%) neonates were full-term at birth (Table 2).

\section{Complications during pregnancy}

Eighty-one (16.6\%) mothers had complications during the index case. Preeclampsia or eclampsia accounted for $43(8.8 \%)$. Besides, 30 (6.1\%) mothers had a medical illness during pregnancy. Two hundred twenty-six (46.2\%) mothers had complications during labor, with the most common complication being the prolonged duration of labor in 103 (21.1\%) (Table 3).

\section{Neonatal characteristics}

Three hundred six (62.6\%) and 378 (77.3\%) newborns were male and admitted within the first day of life, respectively. More than half 274 (56.4\%) of the neonates had a normal birth weight (2500-3999 g). Three-fourths neonates, 350 (71.6\%) were hypothermic upon admission, and 133 (27.2\%) suffered from birth asphyxia at $5 \mathrm{~min}$. (based on the $5 \mathrm{~min}$. APGAR score). Three hundred one (61.1\%) newborns initiated exclusive breastfeeding in the first hour (Table 4).

\section{Treatment modalities}

Four hundred thirty-five (89\%) neonates had received antibiotics and 416 (85.1\%) had intravenous fluids as treatment, while only $72(14.7 \%)$ utilized the kangaroo mother care (Fig. 1).

\section{Proportion and causes of neonatal mortality}

Among admitted newborns, 98 (20\%) died and the remaining survived from admission to discharge in the NICU (Fig. 2). The most common causes of neonatal mortality were complications of preterm 28 (28.58\%), followed by birth asphyxia $22(22.45 \%)$ and neonatal infection 18 (18.36\%) (Fig. 3).

\section{Predictors of neonatal mortality in neonatal intensive care units}

In the multivariable logistic regression analysis, low 5 min. APGAR score, low birth weight, preterm birth, length of hospital stay, febrile illness, and feeding status were independent predictors of neonatal

Table 3 Obstetric and labor complications among mothers whose neonates were admitted to the NICU of public hospitals in eastern Ethiopia, $2018[n=489]$

\begin{tabular}{|c|c|c|c|}
\hline Characteristics & Category & Frequency & Percent \\
\hline \multirow[t]{7}{*}{ Obstetric complications during the current pregnancy } & Yes & 81 & 16.6 \\
\hline & No & 408 & 83.4 \\
\hline & Preeclampsia or eclampsia & 43 & 8.8 \\
\hline & Chorioamnionitis & 8 & 1.6 \\
\hline & Premature rupture of membrane & 18 & 3.7 \\
\hline & Antepartum hemorrhage & 17 & 3.5 \\
\hline & Other & 1 & 0.2 \\
\hline \multirow[t]{9}{*}{ Medical illness during pregnancy } & Yes & 30 & 6.1 \\
\hline & No & 459 & 93.9 \\
\hline & Diabetes mellitus & 5 & 1.0 \\
\hline & Hypertension & 8 & 1.6 \\
\hline & Tuberculosis & 1 & 0.2 \\
\hline & Cardiac disease & 1 & 0.2 \\
\hline & Anemia & 14 & 2.9 \\
\hline & Human immunodeficiency virus & 3 & 0.6 \\
\hline & Others & 2 & 0.4 \\
\hline \multirow[t]{6}{*}{ Complication during labor } & Yes & 226 & 46.2 \\
\hline & No & 263 & 53.8 \\
\hline & Prolonged labor & 103 & 21.1 \\
\hline & Premature rupture of membrane & 62 & 12.7 \\
\hline & Fetal distress & 84 & 17.2 \\
\hline & Cord prolapsed & 8 & 1.6 \\
\hline
\end{tabular}


Table 4 Characteristics of neonates admitted to the NICU of public hospitals in eastern Ethiopia, 2018 [ $n=489$ ]

\begin{tabular}{|c|c|c|c|}
\hline Variable & Category & Frequency & Percent \\
\hline \multirow[t]{2}{*}{ Sex of the newborn } & Male & 306 & 62.6 \\
\hline & Female & 183 & 37.4 \\
\hline \multirow[t]{2}{*}{ Age of neonate on admission } & $\leq$ one day & 378 & 77.3 \\
\hline & >one days & 111 & 22.7 \\
\hline \multirow[t]{5}{*}{ Birth weight } & $<1000 \mathrm{~g}$ & 8 & 1.6 \\
\hline & $1000-1499 \mathrm{~g}$ & 33 & 6.7 \\
\hline & $1500-2499 \mathrm{~g}$ & 145 & 29.7 \\
\hline & $2500-3999 \mathrm{~g}$ & 274 & 56.0 \\
\hline & $\geq 4000 \mathrm{~g}$ & 29 & 5.9 \\
\hline \multirow[t]{3}{*}{ Temperature at admission $\left({ }^{0} \mathrm{c}\right)$} & $<36.5$ & 350 & 71.6 \\
\hline & $36.5-37.5$ & 92 & 18.8 \\
\hline & $>37.5$ & 47 & 9.6 \\
\hline \multirow[t]{4}{*}{ APGAR score at $5 \mathrm{~min}$} & $\leq 3$ & 7 & 1.4 \\
\hline & $4-6$ & 126 & 25.8 \\
\hline & $7-10$ & 251 & 51.3 \\
\hline & Unknown & 105 & 21.5 \\
\hline \multirow[t]{3}{*}{ Initiation of Feeding in 1st hour with } & Nothing per mouth & 152 & 31.1 \\
\hline & Exclusive Breast Feeding & 301 & 61.1 \\
\hline & Formula Feeding & 36 & 7.4 \\
\hline
\end{tabular}

mortality. Preterm neonates were almost three times $(\mathrm{AOR}=2.78 ; 95 \% \mathrm{CI}: 1.17,6.57)$ more likely to die compared with term neonates. Low birth weight babies were two times $(\mathrm{AOR}=2.39 ; 95 \% \mathrm{CI}: 1.04,5.41)$ more likely to die when compared with normal birth weight. Furthermore, newborns with a low $5 \mathrm{~min}$. APGAR score were five times $(\mathrm{AOR}=5.18 ; 95 \% \mathrm{CI}: 2.51$, 10.66) more likely to die compared with $5 \mathrm{~min}$. APGAR score of greater than or equal to seven; length of stay was another variable found to be predictors of neonatal mortality. Newborns who were hospitalized for less than 3 days were nearly four times $(\mathrm{AOR}=3.63$; $95 \% \mathrm{CI}: 1.82$, 7.22) more likely to die than those who were hospitalized for 4-7 days; this implies that the majority of deaths occurred in the first $72 \mathrm{hrs}$. of life. Besides, neonates with fever on admission were nearly seven times $(\mathrm{AOR}=6.68$; 95\% CI: 1.34, 33.13) more likely to die compared with their counterparts. Moreover, neonates for whom breastfeeding was not initiated within the first $24 \mathrm{hrs}$. were twelve times $(\mathrm{AOR}=12.16$; 95\% CI: 5.98, 24.70) more likely to die than those who were on exclusive breastfeeding within the first $24 \mathrm{~h}$ of life (Table 5).

Treatment given to neonates in NICU

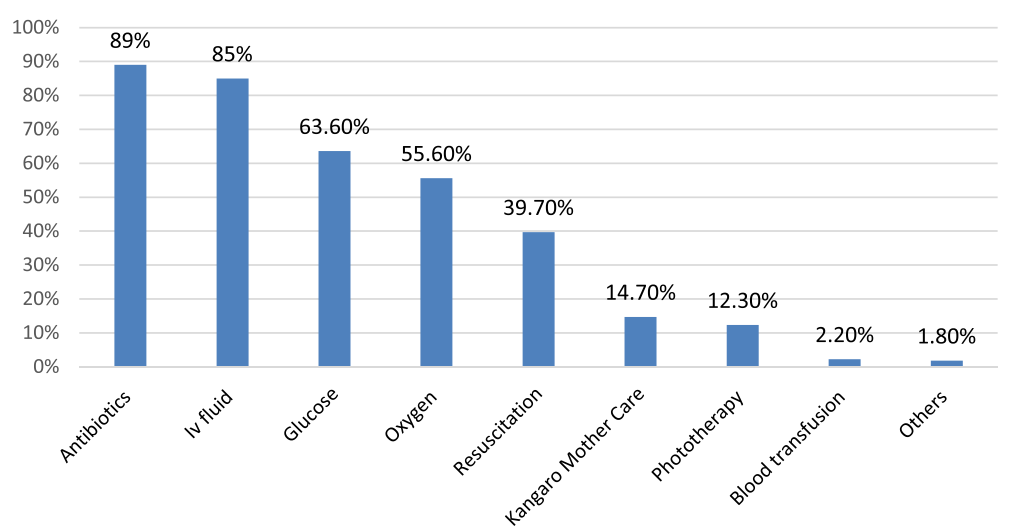

Fig. 1 Treatment modalities delivered to neonates admitted to the NICU in public hospitals in eastern Ethiopia, 2018[n=489] 


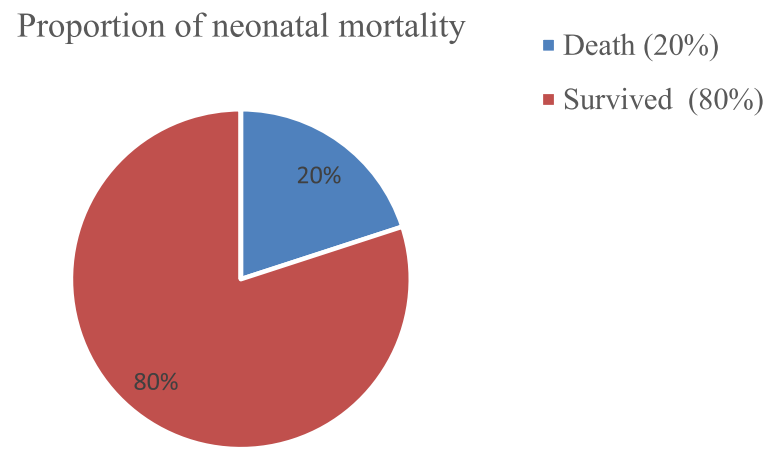

Fig. 2 Proportion of neonatal death among neonates admitted to the NICU of public hospitals in eastern Ethiopia, $2018[n=489]$

\section{Discussion}

Despite advancements in technologies and interventions made for improving the life of newborns, neonatal death remains an unfinished agenda as a serious public health concern in developing countries, including Ethiopia. Therefore, we conducted this prospective study to determine the causes and predictors of neonatal mortality in the NICUs in eastern Ethiopia. Accordingly, the proportion of neonatal deaths was 20\% (95\% CI: 16.7-23.8\%). This resulted mainly from preventable causes, which are unconscionable in the twenty-first century. The present finding is in agreement with studies conducted in Ethiopia and other developing countries such as India (18.69\%), Eastern Nepal (20.2\%), Nigeria (18.8\%), and Central Ethiopia (23.3\%) [16, 19-21]. However, it was greater than the studies carried out in Northern Vietnam (13.9\%), India (7.16\%), Ghana (16\%), South Africa (13.8\%), and Cameroon (15.7\%) [5, 22-25]. These variations between studies might be explained, in part, by the discrepancy in the follow-up time, sample size, and quality of prenatal care delivered in these facilities. Also, the present study was conducted in hospitals with a recently established NICU; this might result in a difference in the distribution of essential equipment and skilled manpower. Additionally, disparities in socioeconomic conditions of the population well as geographical locations could have contributed to the variation.

In the current study, the main causes of death were complications of preterm birth (28.58\%), birth asphyxia (22.45\%), and neonatal infection (18.36\%). This was supported by reports and findings from the WHO, Northern Vietnam, India, Ghana, Nigeria, Cameroon, South Sudan, and Southern and Northern Ethiopia [5, 11, 19, 20, 22-24, 26-30]. The findings of our study showed that more than $70 \%$ of neonatal deaths were attributed to prematurity, neonatal sepsis, and birth asphyxia. This finding suggests the need for intensive neonatal survival interventions targeting the intrapartum period as well as in immediate and early neonatal periods to reduce neonatal mortality.

Birth asphyxia, preterm, low birth weight, and failure to initiate early feeding were significant factors that increased the likelihood of neonatal deaths. These findings are consistent with previous studies in Ethiopia and other countries, in which intrapartum and neonatal conditions were found to be important predictors of neonatal mortality [21, 25, 28, 30-33]. Preterm and low birth weight babies were more likely to be prone to complications such as hypothermia, infections, and birth asphyxia (resulting in tissue hypoxia and multi-organ failure). Therefore, provisions of quality neonatal care, including quality resuscitation, thermal care, and appropriate feeding, are important to avert some of these factors [34-37].

Furthermore, a short duration of less than 3 days of life in the NICU was found to be significantly associated with neonatal death. This is in contrast with a study in the Somali region, where a shorter stay in the NICU was protective against mortality [38]. However, this is consistent with the fact that most neonatal deaths occur in the first $72 \mathrm{~h}$ after birth. This suggests that any intervention at this critical time has a significant contribution to

\section{Precent}

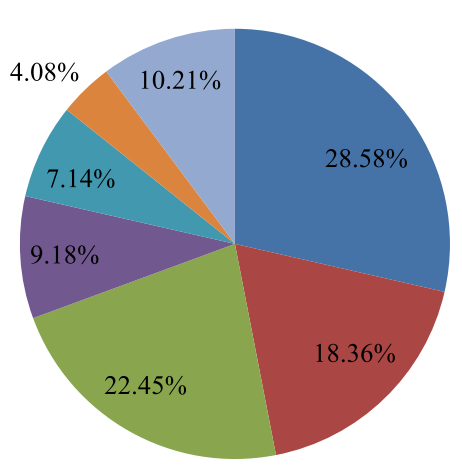

$$
\begin{aligned}
& \text { Preterm } \\
& \text { Infection } \\
& \text { Birth asphyxia } \\
& \text { Miconium Aspiration Syndrome } \\
& \square \text { Respiratory Distresses Syndrome } \\
& \text { Congenital malformation } \\
& \text { Others }
\end{aligned}
$$

Fig. 3 Causes of neonatal mortality among neonates admitted to the NICU of public hospitals in eastern Ethiopia 2018 [ $n=98]$ 
Table 5 Multivariable analysis for predictors of neonatal mortality among neonates admitted to the NICU of public hospitals in eastern Ethiopia, $2018[n=489]$

\begin{tabular}{|c|c|c|c|c|c|}
\hline \multicolumn{6}{|l|}{ Neonatal mortality } \\
\hline Characteristics & Died & Improved & COR & AOR & $P$-value \\
\hline \multicolumn{6}{|l|}{ Maternal Age } \\
\hline $21-30$ years & 51 & 228 & 1 & & \\
\hline$<20$ years & 29 & 80 & $1.62(0.96,2.73)$ & $1.50(0.67,3.34)$ & .335 \\
\hline $31-40$ years & 17 & 78 & $0.97(0.53,1.78)$ & $1.85(0.76,4.48)$ & .212 \\
\hline$>40$ years & 1 & 5 & $0.89(0.10,7.82)$ & $2.40(0.23,24.89)$ & .532 \\
\hline \multicolumn{6}{|l|}{ Marital status } \\
\hline Married & 88 & 364 & 1 & 1 & \\
\hline Single & 9 & 19 & $1.96(0.86,4.48)$ & $1.33(0.35,5.03)$ & .766 \\
\hline Others & 1 & 8 & $0.52(0.06,4.18)$ & $1.62(0.15,16.94)$ & .543 \\
\hline \multicolumn{6}{|l|}{ Parity } \\
\hline Multi-Para & 50 & 233 & 1 & 1 & \\
\hline Primi-para & 48 & 158 & $1.42(0.91,2.21)$ & $1.94(0.93,4.05)$ & .680 \\
\hline \multicolumn{6}{|l|}{ Place of delivery } \\
\hline Inborn (in this hospital) & 253 & 127 & 1 & 1 & \\
\hline Other facility & 46 & 41 & $0.56(0.29,1.09)$ & $0.50(0.17,1.51)$ & .275 \\
\hline Home & 16 & 6 & $0.35(0.08,1.53)$ & $0.26(0.03,2.40)$ & .205 \\
\hline \multicolumn{6}{|l|}{ Duration of labor } \\
\hline $4-12$ hrs. & 177 & 111 & 1 & 1 & \\
\hline less than $4 \mathrm{hrs}$. & 27 & 16 & $0.80(0.35,1.81)$ & $0.45(0.12,1.63)$ & .225 \\
\hline More than $12 \mathrm{hrs}$. & 111 & 47 & $0.69(0.41,1.14)$ & $0.62(0.30,1.25)$ & .184 \\
\hline \multicolumn{6}{|l|}{ Mode of delivery } \\
\hline Spontaneous vaginal & 221 & 117 & 1 & 1 & \\
\hline Cesarean section & 79 & 43 & $1.23(0.73,2.05)$ & $1.00(0.47,2.10)$ & .460 \\
\hline Instrumental & 15 & 14 & $2.78(1.24,6.17)$ & $1.34(0.40,4.44)$ & .944 \\
\hline \multicolumn{6}{|l|}{ Length of hospital stay } \\
\hline 4-7 days & 172 & 57 & 1 & 1 & \\
\hline$<3$ days & 68 & 92 & $4.03(2.43,6.67)$ & $3.63(1.82,7.22)^{*}$ & .000 \\
\hline$>7$ days & 75 & 25 & $0.77(0.35,1.63)$ & $0.61(0.23,1.58)$ & .310 \\
\hline \multicolumn{6}{|l|}{ Gestational age at birth } \\
\hline Term (37-42 weeks) & 227 & 92 & 1 & 1 & \\
\hline Preterm (<37 weeks) & 82 & 78 & $3.56(2.23,5.66)$ & $2.78(1.17,6.56)^{*}$ & .020 \\
\hline Post term (> 42 weeks) & 6 & 4 & $4.65(1.25,17.19)$ & $4.54(0.83,24.70)$ & .051 \\
\hline \multicolumn{6}{|l|}{ Birth weight } \\
\hline $2500-3999 \mathrm{~g}$ & 211 & 86 & 1 & 1 & \\
\hline Less than $2499 \mathrm{~g}$ & 77 & 86 & $3.46(2.17,5.49)$ & $2.39(1.04,5.49)^{*}$ & .040 \\
\hline$\geq 4000 \mathrm{~g}$ & 27 & 2 & $0.23(0.03,1.73)$ & $0.67(0.06,6.80)$ & .858 \\
\hline \multicolumn{6}{|l|}{$5 \mathrm{~min}$. APGAR score } \\
\hline $7-10$ & 188 & 63 & 1 & 1 & \\
\hline$\leq 6$ & 68 & 65 & $5.62(3.32,9.47)$ & $5.18(2.51,10.66)^{*}$ & .000 \\
\hline Unrecorded & 59 & 46 & $1.33(0.67,2.60)$ & $2.50(0.82,7.54)$ & .092 \\
\hline \multicolumn{6}{|l|}{ Temperature on admission } \\
\hline $36.5-37.5 c^{0}$ & 64 & 28 & 1 & 1 & \\
\hline
\end{tabular}


Table 5 Multivariable analysis for predictors of neonatal mortality among neonates admitted to the NICU of public hospitals in eastern Ethiopia, 2018 [ $n=489$ ] (Continued)

\begin{tabular}{|c|c|c|c|c|c|}
\hline \multicolumn{6}{|c|}{ Neonatal mortality } \\
\hline Characteristics & Died & Improved & COR & $\mathrm{AOR}$ & $P$-value \\
\hline$<36.5 c^{0}$ & 218 & 132 & $3.37(1.56,7.23)$ & $2.75(0.97,7.78)$ & .057 \\
\hline$>37.5 c^{0}$ & 33 & 14 & $1.25(0.38,4.05)$ & $6.68(1.35,33.13)^{*}$ & .020 \\
\hline \multicolumn{6}{|c|}{ Initiation of Feeding } \\
\hline EBF & 237 & 64 & 1 & 1 & \\
\hline NPO & 53 & 99 & $16.71(9.32,29.94)$ & $12.16(5.98,24.70)^{*}$ & .000 \\
\hline $\mathrm{FF}$ & 25 & 11 & $2.69(0.93,7.80)$ & $1.71(0.47,6.15)$ & .077 \\
\hline
\end{tabular}

*statistically significant at $P \leq 0.05 ; E B F$ exclusive breastfeeding, NPO nothing per month, $F F$ formula feeding

saving the life of the neonates [38, 39]. Besides, febrile illness $\left(\geq 37.5^{\circ} \mathrm{c}\right)$ on admission was found to be a significant predictor of neonatal mortality. This is likely due to the high proportion of neonatal infections in the present study setting.

This finding emphasizes the need to improve the quality of care in health facilities. In particular, we strongly believe that achieving high-quality intrapartum and postnatal care is required to improve neonatal health. A significant proportion of neonatal deaths can be avoided by appropriate resuscitation care [40, 41]. Most of the infection-related deaths can be avoided by treating maternal infections during pregnancy, ensuring a clean birth, care of the umbilical cord, and exclusive breastfeeding [42, 43]. There is a range of available evidence-based interventions that can improve the survival of premature and lowbirth-weight newborns. The promotion of early and exclusive breastfeeding, prevention, and treatment of hypothermia, including kangaroo mother care [43, 44], and topical skin-cleansing with chlorhexidine may reduce morbidity and mortality secondary to infection $[45,46]$. The gap for the care of mothers and babies in the first few days of life is important even when women deliver in facilities. Moreover, communities and decision-makers need to be informed that neonatal deaths are a huge portion of child deaths, and need therefore to receive adequate attention.

The strengths of this study were that the inclusion of multiple facilities and prospective follow-up of neonates from admission to discharge or death. In addition, it was carried out without sampling; therefore, the possibility of sampling error was eliminated. However, the relatively small sample size and wide $\mathrm{CI}$ in the multivariable model associated with some variables may undermine the strength of this study. The study was conducted at hospitals; therefore, neonates delivered at home and died at home could be missed. Hence, this study does not reflect population-based neonatal mortality rather; it reflects institution-based neonatal death in the given period.

\section{Conclusion}

The proportion of facilities-based neonatal mortality was unacceptably high. The common causes of neonatal death were preterm birth, birth asphyxia, infection, respiratory morbidity, and congenital malformation. Preterm births, low birth weight, low $5 \mathrm{~min}$. APGAR score, short stay in the NICU, failure to initiate early breastfeeding, and temperature $\left(\geq 37.5^{\circ} \mathrm{C}\right)$ at admission were significant predictors of neonatal mortality in eastern Ethiopia. Efforts to address birth asphyxia, neonatal infections, and preterm birth are critical to achieving survival goals in newborns. Improving the timing and quality of ANC is essential for early detection, anticipating high-risk newborns, and timely interventions. Furthermore, early initiation of feeding and a better referral linkage to tertiary facilities could contribute to the reduction of neonatal mortality and morbidity in this setting.

\section{Abbreviations}

ANC: Antenatal Care; AOR: Adjusted Odd Ratio; APGAR: Appearance, Pulse, Grimace, Activities, and Respiration; Cl: Confidence Interval; CSA: Central

Statistical Agency; EBF: Exclusive Breast Feeding; MAS: Meconium Aspiration Syndrome; NICU: Neonatal Intensive Care Unit; NMR: Neonatal Mortality Rate; RDS: Respiratory Distress Syndrome; SDGs: Sustainable Development Goals; SPSS: Statistical Package for Social Sciences; UNICEF: United Nations International Children's Emergency Fund; WHO: World Health Organization

\section{Acknowledgments}

We would like to thank Haramaya University, research and project affairs for financial and unreserved technical support. We would also like to extend our gratitude to the health Bureau, hospital heads, and the study participants for collaborations. Last but not the least, we would like to thank Dr. Tara Wilfong (MD, MPH) and Mr. Fitsum Weldegebreal (Assistant Professor) for their wonderful feedback on the English language and scientific content of the manuscript.

\section{Authors' contributions}

$A D, Y S$, and NT conceived and designed the study. AD drafted the manuscript. BG, FA, TW, KA, and AA extensively reviewed the manuscript and incorporated intellectual input. All authors read, provided feedback, and approved the final version of the manuscript.

\section{Funding}

This work was financially supported by Haramaya University, Ethiopia. The funder has no role in the study selection, data collection, analysis, conclusion, and recommendation.

Availability of data and materials

All the data of this study are available from the corresponding author upon reasonable request. 


\section{Ethics approval and consent to participate}

Ethical clearance was obtained from the Institutional Health Research Ethics Review Committee of the College of Health and Medical Sciences, Haramaya University. Following approval, a written official letter of cooperation was given to the regional health Bureaus and facilities. Informed written consent was obtained from all participants. Furthermore, confidentiality was assured throughout the process.

\section{Consent for publication}

Not applicable.

\section{Competing interests}

The authors declare that they have no competing interests.

\section{Author details}

${ }^{1}$ School of Nursing and Midwifery, College of Health and Medical Sciences, Haramaya University, Po. Box 235, Harar, Ethiopia. ${ }^{2}$ School of Medicine, College of Health and Medical Sciences, Haramaya University, Harar, Ethiopia. ${ }^{3}$ School of Pharmacy, College of Health and Medical Sciences, Haramaya University, Harar, Ethiopia.

Received: 11 December 2019 Accepted: 25 March 2020

Published online: 14 April 2020

\section{References}

1. UNICEF, WHO WB \&UN. Levels and Trends in Child Mortality - Report 2018 Estimates developed by the UN inter-agency Group for Child Mortality Estimation [internet]. New York USA: UNICEF; 2018. p. 8-48. Available from: https://data.unicef.org/wp-content/uploads/2018.

2. WHO. WHO | Child mortality [Internet]. 2016. Available from: http://www. who.int/maternal_child.

3. Oza S, Lawn JE, Hogan DR, Mathers C, Cousens SN. Neonatal cause-of-death estimates for the early and late neonatal periods for 194 countries: 20002013. Bull World Health Organ. 2015;93(1):19-28.

4. Ali SR, Ahmed S, Lohana H. Disease patterns and outcomes of neonatal admissions at a secondary care hospital in Pakistan. Sultan Qaboos Univ Med J. 2013;13(3):418-21.

5. UNICEF, WHO, World Bank U-DPD. Levels and trends in child mortality [Internet]. New York; 2015. Available from: http://www.who.int/maternal_ child_adolescent/documents/levels_trends_child_mortality.

6. Omoigberale Al, Sadoh WE, Nwaneri DU. A 4 year review of neonatal outcome at the University of Benin teaching hospital, Benin City. Niger J Clin Pract. 2010;13(3):321-5.

7. Seoud I, El-din RMG, Said RN, Hessin HA. Predictors of neonatal mortality in intensive care unit in Children's hospital. Alexandria J Pediatr. 2005;19(1):93-7.

8. Mekonnen Y, Tensou B, Telake DS, et al. Neonatal mortality in Ethiopia: trends and determinants. BMC Public Health. 2013;13:483. https://doi.org/10. 1186/1471-2458-13-483.

9. ICF CSA (CSA) [Ethiopia] and. Ethiopia Demographic and Health Survey 2016. Key Indicators Report. Addis Ababa, Ethiopia, and Rockville Maryland, USA: CSA and ICF; 2016.

10. WHO |. WHO | Newborn death and illness [Internet]. Geneva 27, Switzerland: WHO Press, World Health Organization; 2011. Available from: http://www. who.int/pmnch/media/press.

11. World Bank. Ethiopia Neonatal mortality rate, World Development Indicators, The World Bank 1960-2017 [Internet]. 2018. Available from: https://knoema.com/atlas/Ethiopia/Neonatal-mortality-rate.

12. World Bank. World Development. Washington, DC: World Bank.: License: Creative Commons Attribution CC BY 3.0; 2013. p. 2-6.

13. Demisse AG, Alemu F, Gizaw MA, Tigabu Z. Patterns of admission and factors associated with neonatal mortality among neonates admitted to the neonatal intensive care unit of University of Gondar Hospital, Northwest Ethiopia. Pediatr Heal Med Ther. 2017;8:57-64.

14. Worku B, Kassie A, Mekasha A, Tilahun B, Worku A. Predictors of early neonatal mortality at a neonatal intensive care unit of a specialized referral teaching hospital in Ethiopia. J Health Dev. 2012;26(3):200-7.

15. $\mathrm{FMOH}$. Federal Democratic Republic of Ethiopia Ministry of Health: Health Sector Development Programme IV 2010/11-2014/15 [Internet]. Vol. IV. 2010. p. 114. Available from: http://www.nationalplanningcycles.org/sites.
16. Tekleab AM. Amaru GM and TYA. Reasons for admission and neonatal outcome in the neonatal care unit of a tertiary care hospital in Addis Ababa : a prospective study. Res Reports Neonatol. 2016;6(2016):17-23.

17. WHO. Every Newborn Progress Report May 2015 [Internet]. Geneva 27, Switzerland: WHO Press, World Health Organization, 20 Avenue Appia,; 2015. Available from: www.everynewborn.org\%0Awww.everynewborn.org.

18. World Health Organization. Promoting Optimal Fetal Development [Internet]. GENEVA, Switzerland: World Health Organization; 2006. p. 3-8. Available from: http://www.who.int/nutrition/.

19. Prasad VS. Causes of morbidity and mortality in neonates admitted in Government Medical College,Haldwani in Kumaun Region(Uttarakhand)India. J Pharm Biomed Sci. 2011;8(8):1-4.

20. Shah GS, Yadav S, Thapa ASL. Clinical profile and outcome of neonates admitted to neonatal intensive care unit (NICU) at a tertiary Care Centre in Eastern Nepal. J Nepal Paediatr Soc. 2013;4(3):1511-6.

21. Elizabeth IU, Oyetunde MO. Pattern of diseases and care outcomes of neonates admitted in special care baby unit of university college hospital, Ibadan, Nigeria from 2007 to 2011. IOSR J Nurs Health Sci. 2015;4(3):62-71.

22. Ndombo PK, Ekei QM, Tochie JN, Temgoua MN, Angong FTE, Ntock FN, et al. A cohort analysis of neonatal hospital mortality rate and predictors of neonatal mortality in a sub-urban hospital of Cameroon. Ital J Pediatr. 2017; 43(1):52.

23. Miles M, Dung KTK, Ha LT, Liem NT, Ha K, Hunt RW, et al. The cause-specific morbidity and mortality, and referral patterns of all neonates admitted to a tertiary referral hospital in the northern provinces of Vietnam over a one year period. PLoS One. 2017;12(3):1-12.

24. Sridhar PV, Thammanna PS, Sandeep M. Morbidity pattern and hospital outcome of neonates admitted in a tertiary care teaching hospital, Mandya. Int J Sci Stud. 2015;3(6):126-9.

25. Walana W, Acquah Ekuban KS, Abdul-Mumin A, Naafu B, Aruk E, KS VKE, et al. Pattern, causes and treatment outcomes of neonatal admission in the Tamale teaching hospital. Clin Mother Child Health. 2016;13:252. https://doi. org/10.4172/2090-7214.100025.

26. WHO. Guidelines on Basic Newborn Resuscitation [Internet]. World Health Organization. WHO Press, World Health Organization, 20 Avenue Appia, 1211 Geneva 27, Switzerland; 2012. Available from: https://www.who.int/ maternal_child_adolescent.

27. Hoque M, Haaq S, Islam R. Causes of neonatal admissions and deaths at a rural hospital in KwaZulu-Natal, South Africa. South African J Epidemiol Infect. 2011;26(1):26-9.

28. Salve DS, Inamdar IF, Sarawade S, Doibale MK, Tambe SH, Sahu PC. Study of profile and outcome of the newborns admitted in neonatal intensive care unit (NICU) at tertiary Care Hospital in a City of Maharashtra. Int J Heal Sci Res. 2015;5(October 2015):18-23.

29. Kokeb M, Desta T. Institution based prospective cross-sectional study on patterns of neonatal morbidity at Gondar University hospital neonatal unit, north-West Ethiopia. Ethiop J Health Sci [Internet]. 2016;26(1):73-9.

30. Thomson J, Schaefer M, Caminoa B, Kahindi D, Hurtado N. Improved Neonatal Mortality at a District Hospital in Aweil, South Sudan. J Trop Pediatr [Internet]. 2016;63(3):189-95.

31. Debelew GT, Afework MF, Yalew AW. Determinants and causes of neonatal mortality in jimma Zone, Southwest Ethiopia: A multilevel analysis of prospective follow up study. PLoS One. 2014;9(9).

32. Kang G, Lim JY, Kale AS, Lee LY. Adverse effects of young maternal age on neonatal outcomes. Singap Med J. 2015;56(3):157-63.

33. Mengesha HG, Sahle BW. Cause of neonatal deaths in northern Ethiopia : a prospective cohort study. BMC Public Health. 2017;17(62):1-8.

34. Orsido T, Asseffa NA, Berheto TM. Predictors of neonatal mortality in neonatal intensive care unit at referral Hospital in Southern Ethiopia: a retrospective cohort study. BMC Pregnancy Childbirth. 2019;19(1):1-9.

35. Liu KC, Joseph JA, Nkole TB, Kaunda E, JSA S, Chi BH, et al. Predictors and pregnancy outcomes associated with a newborn birth weight of $4000 \mathrm{~g}$ or more in Lusaka, Zambia. Int J Gynecol Obstet. 2013;122(2):150-5.

36. Abdallah Y, Namiiro F, Mugalu J, Nankunda J, Vaucher Y, McMillan D. Is facility based neonatal care in low resource setting keeping pace? A glance at Uganda's National Referral Hospital. Afr Health Sci. 2016;16(2): 347-55.

37. Dassah ET, Odoi AT, Opoku BK. Stillbirths and very low Apgar scores among vaginal births in a tertiary hospital in Ghana: a retrospective cross-sectional analysis. BMC Pregnancy Childbirth. 2014;14(1):289. 
38. Abdifatah EF, Abdulahi HA, AT. Trends of admission and predictors of neonatal mortality : A hospital based retrospective cohort study in Somali region of. PLoS One. 2018;13(9):e0203314..

39. Hedstrom A, Ryman T, Otai C, Nyonyintono J, McAdams RM, Lester D, et al. Demographics, clinical characteristics and neonatal outcomes in a rural Ugandan NICU. BMC Pregnancy Childbirth. 2014;14(1):327.

40. Wall SN, Lee AC, Niermeyer S, et al. Neonatal resuscitation in low-resource settings: what, who, and how to overcome challenges to scale up? Int J Gynaecol Obstet. 2009;107(Suppl 1):S47-64. https://doi.org/10.1016/j.ijgo. 2009.07.013.

41. Bhutta ZA, Darmstadt GL, Hasan BS, Haws RA. Community-based interventions for improving perinatal and neonatal health outcomes in developing countries: a review of the evidence. Pediatrics. 2005;115(2):519-617.

42. Brahmbhatt $\mathrm{H}$, Gray RH. Breastfeeding and the prevention of infant mortality. Lancet. 2000;355(9212):1370.

43. Conde-Agudelo A, Díaz-Rossello JL. Kangaroo mother care to reduce morbidity and mortality in low birthweight infants. Cochrane Database Syst Rev. 2016;2016(8).

44. Quasem I, Sloan NL, Chowdhury A, Ahmed S, Winikoff B, Chowdhury AMR. Adaptation of kangaroo mother care for community-based application. J Perinatol. 2003;23(8):646-51.

45. Gelano TF, Bacha YD, Abate D. Effect of chlorhexidine cord application on prevention of neonatal sepsis in developing countries: systematic review and meta-analysis. Int J Health Sci (Qassim). 2019:13(1):40-51.

46. Seid SS, Ibro SA, Ahmed AA, Olani Akuma A, Reta EY, Haso TK, et al. Causes and factors associated with neonatal mortality in neonatal intensive care unit (NICU) of Jimma University medical center, Jimma, south West Ethiopia. Pediatr Heal Med Ther. 2019;10(2019):39-48.

\section{Publisher's Note}

Springer Nature remains neutral with regard to jurisdictional claims in published maps and institutional affiliations.

Ready to submit your research? Choose BMC and benefit from:

- fast, convenient online submission

- thorough peer review by experienced researchers in your field

- rapid publication on acceptance

- support for research data, including large and complex data types

- gold Open Access which fosters wider collaboration and increased citations

- maximum visibility for your research: over $100 \mathrm{M}$ website views per year

At $\mathrm{BMC}$, research is always in progress.

Learn more biomedcentral.com/submissions 